\title{
PEMANFAATAN KARBON AKTIF DARI LIMBAH SEKAM PADI DAN BONGGOL JAGUNG UNTUK MENGURANGI KADAR PENCEMAR PADA SUNGAI SEKANAK
}

\section{THE UTILIZATION OF ACTIVATED CARBON FROM RICE HUSK AND CORNCOB AS ACTIVE CARBONS TO REDUCE OF POLLUTION LEVELS IN SEKANAK RIVER}

\author{
${ }^{1 *}$ Kiagus Ahmad Roni, ${ }^{3)}$ Evy Kurniati, ${ }^{4)}$ Legiso, ${ }^{2)}$ Tri Susanto \\ ${ }^{134)}$ Program Studi Teknik Kimia, Fakultas Teknik, Universitas Muhammadiyah Palembang \\ ${ }^{2)}$ Balai Riset dan Standardisasi Industri Palembang \\ E-mail*: kiagusaroni@gmail.com
}

Diterima : 24 Februari 2020

Direvisi : 29 April 2020

Disetujui: 13 Juli 2020

\begin{abstract}
ABSTRAK
Sungai Sekanak merupakan salah satu sungai yang ada di kawasan pemukiman yang padat penduduk, pusat perekonomian serta pusat pemerintahan. Sungai sekanak memiliki tiga buah kolam retensi, yaitu Siti Khodijah, Kambang Iwak Besar, dan Kambang Iwak Kecil. Kondisi sungai sekanak yang bau, dan kotor, disebabkan oleh beberapa parameter yaitu $\mathrm{COD}, \mathrm{BOD}, \mathrm{TDS}, \mathrm{pH}$, dan $\mathrm{Fe}\left(\mathrm{Fe}^{2+}, \mathrm{Fe}^{3+}\right.$ terlarut, dan $\mathrm{Fe}^{3+}$ ). Sehingga dibutuhkan komposisi dan material yang pas untuk mengurangi kadar pencemaran pada air sungai sekanak. Dengan ini diharapkan dapat memperoleh komposisi dan material yang optimal untuk menurunkan nilai $\mathrm{COD}$, TDS, BOD, dan $\mathrm{Fe}$, serta meningkatkan nilai $\mathrm{pH}$ air pada sungai sekanak yang berdasarkan dengan standar mutu air. Berdasarkan penelitian yang telah dilakukan diperoleh komposisi dan material yang optimal yang mampu menurunkan kadar $\mathrm{COD}, \mathrm{BOD}, \mathrm{TDS}, \mathrm{pH}$, dan $\mathrm{Fe}\left(\mathrm{Fe}^{2+}, \mathrm{Fe}^{3+}\right.$ terlarut, dan $\mathrm{Fe}^{3+}$ ) yaitu pada karbon aktif dari limbah bonggol jagung dengan proses karbonisasi $300^{\circ} \mathrm{C}$, $25 \% \mathrm{H}_{3} \mathrm{PO}_{4}$ sebagai aktivator yang menggunakan bahan baku bonggol jagung, serta waktu aktivasi selama 24 jam. Bonggol jagung dengan $\mathrm{pH} 7,18$, sehingga didapat senilai COD sebesar $8 \mathrm{mg} / \mathrm{L}, \mathrm{BOD}$ $1,5 \mathrm{mg} / \mathrm{L}$, TDS $102 \mathrm{mg} / \mathrm{L}$, dan kadar Fe $0 \mathrm{mg} / \mathrm{L}$. Sedangkan karbon aktif dari sekam padi yang diproses dengan karbonisasi $300^{\circ} \mathrm{C}, 25 \% \mathrm{H}_{3} \mathrm{PO}_{4}$, serta waktu aktivasi memiliki nilai pH sebesar 7,02 dari 6,30 , sehingga diperoleh nilai COD 10mg/L, BOD 1,7mg/L, TDS 104mg/L, dan Fe 0mg/L.
\end{abstract}

Kata kunci: bonggol jagung, karbon aktif, sekam padi, sungai sekanak

\begin{abstract}
Sekanak River is one of the rivers in a densely populated residential area, the center of the economy and the center of government. Sekanak river has three retention ponds, namely Siti Khodijah, Kambang Iwak Besar, and Kambang Iwak Kecil. The odor and dirty conditions of the Sekanak river are caused by several parameters, namely COD, BOD, TDS, $\mathrm{pH}$, and $\mathrm{Fe}\left(\mathrm{Fe}^{2+}\right.$, dissolved $\mathrm{Fe}^{3+}$, and $\mathrm{Fe}^{3+}$ ) So that the right composition and material is needed to reduce the level of pollution in the Sekanak river water. With this, it is hoped that the optimal composition and material can be obtained to reduce the values of COD, TDS, $B O D$, and Fe, as well as increase the $\mathrm{pH}$ value of water in the Sekanak river which is based on water quality standards. Based on the research that has been done, it is found that the optimal composition and material is able to reduce the levels of $\mathrm{COD}, \mathrm{BOD}, \mathrm{TDS}, \mathrm{pH}$, and $\mathrm{Fe}\left(\mathrm{Fe}^{2+}\right.$, dissolved $\mathrm{Fe}^{3+}$, and $\left.\mathrm{Fe}^{3+}\right)$, namely on activated carbon from corncob waste with a carbonization process of $300^{\circ} \mathrm{C}, 25 \% \mathrm{H}_{3} \mathrm{PO}_{4}$ as an activator that uses corncob raw material, and the activation time is 24 hours. Corn cobs with a pH of 7.18 , in order to obtain COD values of $8 \mathrm{mg} / \mathrm{L}, B O D 1.5 \mathrm{mg} / \mathrm{L}$, TDS $102 \mathrm{mg} / \mathrm{L}$, and Omg / $L$ of Fe levels. Meanwhile, activated carbon from rice husks processed by carbonization of $300^{\circ} \mathrm{C}, 25 \% \mathrm{H}_{3} \mathrm{PO}_{4}$, and TDS $104 \mathrm{mg} / \mathrm{L}$, and Fe Omg / L.
\end{abstract}

Keywords: activated carbon, corncobs, rice husks, sekanak river 


\section{PENDAHULUAN}

ungai yang merupakan salah satu sumber air yang digunakan oleh masyarakat sekitar. Masyarakat menggunakan air sungai sebagai sumber air bersih, air minum, sumber irigasi, sarana transportasi serta merupakan lahan untuk perikanan. Selain itu, aktivitas industri serta rumah tangga seperti mencuci, dan mandi dapat menjadi sumber menurunnya kualitas dari air sungai (Soemarwoto, 2003). Sungai merupakan sumber air terbesar untuk memenuhi kebutuhan makhluk hidup. Air sungai yang mengair (flowing resources), mengakibatkan disaat dibagian hulu sungai mengalami pencemaran dan kualitasnya menurun, maka bagian hilir juga akan mengalami hal yang sama. Disaat pencemaran dibagian hulu terjadi maka berdampak pada biaya sosial di bagian hilir, serta disaat pelestarian dilakukan di bagian hulu maka akan memberikan manfaat pada bagian hilir (Azwir, 2006).

TDS (Total Dissolve Solid) merupakan unsur yang terlarut (organik dan anorganik) yang ada di dalam larutan. TDSmeter menunjukkan total unsur yang larut didalam Part Per Million (PPM) atau sama dengan milligram per Liter ( $\mathrm{mg} / \mathrm{L})$.

BOD adalah jumlah oksigen yang dibutuhkan oleh bakteri saat mengurai bahan organik terhadap $1000 \mathrm{~mL}$ air limbah selama fermentasi ( $5 \times 24$ jam pada suhu $\left.20^{\circ} \mathrm{C}\right)$. COD yaitu total oksigen yang diperlukan oleh oksidator dalam mengoksidasi unsur organik untuk $1000 \mathrm{~mL}$ air limbah. Nilai BOD cenderung lebih rendah dibandingkan dengan nilai dari COD, dikarenakan terdapat unsur yang stabil (tidak terurai) disaat pengujian BOD dapat dioksidasi dalam uji COD. Selain itu, bahan organik yang melebihi batas, mampu menimbulkan beberapa dampak buruk, antara lain bau, warna, serta rasa.

Sungai yang digunakan untuk keperluan domestik, kemungkinan besar adanya ikatan logam besi dengan senyawa anion yang membentuk $\mathrm{FeCl}_{2}, \mathrm{Fe}\left(\mathrm{HCO}_{3}\right)$, dan $\mathrm{FeSO}_{4}$. Sehingga ion ferri akan mengendap dan membuat warna kemerahan pada bak mandi, perabot rumah tangga yang berbahan porcelain, pipa air, serta pakaian. Tingkat larutnya besi dipengaruhi juga oleh menurunnya kadar $\mathrm{pH}$ pada air. Dalam air sungai, besi berada sebagai $\mathrm{Fe}^{2+}, \mathrm{Fe}^{3+}$ terlarut, dan $\mathrm{Fe}^{3+}$ dalam bentuk senyawa organik berupa koloidal (Effendi, 2003).

Karbon aktif adalah arang yang dibuka pori-porinya dengan cara proses pemanasan dengan suhu tinggi atau dengan dikontakkan dengan bahan kimia. Sehingga mampu menjadi adsorben dan memiliki daya serap yang tinggi (Yustinah, 2011). Karbon aktif banyak dimanfaatkan sebagai penyerap cairan beracun, bau busuk serta proses penjernihan air (Akhmad, 2012). Aktivator yang sering digunakan antara lain asam fosfat, zink klorida dan kalium hidroksida menunjukkan bahwa aktivator terbaik yaitu asam fosfat (Faujiah, 2012). Asam fosfat merupakan aktivator terbaik jika dibandingkan dengan asam sulfat (Budiono, 2009). Teknologi pengolahan lanjutan dalam pembuatan karbon aktif mampu memberikan nilai tambah yang lebih tinggi jika ditinjau dari sisi penggunaan dan nilai ekonomisnya (Hendra,2008).

Sekam padi adalah bagian kulit terluar dari padi, dan biasanya sekam padi ini akan di peroleh sekitar $25 \%$ dari setiap penggilingan padi yang kemudian akan menjadi limbah biomassa (Haryadi, 2006). Sekam padi pada umumnya digunakan dalam proses penjernihan air dengan tahapan filtrasi, koagulasi serta adsorpsi (Sitanggang, 2015).

Bonggol jagung adalah bagian jagung yang keberadaannya setelah biji dipipil (Tangenjaja, 2006). Bonggol jagung merupakan bagian terbesar dari batang jagung (50\%), daun (20\%), bonggol (20\%) dan kulit jagung (10\%) dari jumlah keseluruhan hasil samping produksi tanaman jagung (Suryani, 2009). Bonggol jagung memiliki komposisi kimia antara lain, 8,38\% air, 0,67\% nitrogen, 46,69\% oksigen, 43,42\% karbon, 0,07 sulfur, dan abu sebesar 2,30 (Septiningrum, 2011). 
Adsorpsi kimia (Chemisorption) merupakan proses penyerapan suatu unsur yang terjadi sebab adanya ikatan kimia antara molekul zat terlarut (solute) dan molekul adsorben. Adsorpsi memiliki sifat sangat eksotermis dan irreversible (Rahmawati, 2012).

Aktivasi kimia merupakan proses pemutusan rantai karbon dari senyawa organik dengan pemakaian bahan-bahan kimia (Sembiring, 2003). Pembuatan karbon aktif dengan aktivator $\mathrm{H}_{3} \mathrm{PO}_{4}$ perendaman selama $18,20,22$, dan 24 jam, kondisi optimum didapat perendaman 24 jam, semakin lama perendaman daya serapnya semakin besar hingga pada waktu 24 jam, daya serap terhadap larutan iodium semakin tinggi (Sani, 2011).

Semakin besar konsentrasi dari larutan kimia, maka pori-pori yang akan terbuka akan semakin banyak. Sehingga daya serap dari adsorben akan semakin tinggi. (Kurniati, 2008).

Pemilihan sungai sekanak menjadi sumber sampel yang akan di teliti, dikarenakan disekitar sungai sekanak merupakan daerah padat pemukiman penduduk, sehingga besar kemungkinan air sungai tersebut sudah mengalami pencemaran dan agar dapat dipakai kembali oleh masyarakat maka butuh dilakukan pengolahan air. Selain air sungai yang diolah agar aman di konsumsi oleh masyarakat sekitar, aliran sungai yang ada disebelah kantor walikota juga rencananya akan dijadikan tempat destinasi wisata baru sehingga kadar pencemarannya harus di kurangi. Oleh karena itu peneliti mencoba menggunakan limbah sekam padi dan bonggol jagung sebagai bahan baku pembuatan karbon aktif, dengan tujuan agar mampu mengurangi kadar pencemar pada air sungai sekanak.

\section{METODOLOGI}

Bahan yang digunakan pada penelitian ini, yaitu sekam padi, bonggol jagung, air Sungai Sekanak, larutan asam phospat $\left(\mathrm{H}_{3} \mathrm{PO}_{4}\right)$. Peralatan yang digunakan antara lain furnace, penggerus, sieving, $\mathrm{pH}$ meter, spatula, pengaduk, neraca analitik, bola karet, kertas saring, desikator, buret, neraca analitik, oven, dan peralatan gelas yang umum digunakan di laboratorium

Proses penelitian terdiri dari tiga tahap, yaitu pembuatan karbon aktif dari Sekam Padi dan karbon aktif dari bonggol jagung, Perlakuan air sungai sekanak terhadap karbon aktif untuk beberapa parameter, dan analisis data.

Proses pembuatan karbon aktif terdiri atas tiga tahapan yaitu proses persiapan, karbonisasi dan aktivasi. Untuk tahap awal, sekam padi dan bonggol jagung digunakan sebanyak $2 \mathrm{~kg}$, yang kemudian dipanaskan dengan menggunakan sinar matahari hingga kering. Selanjutnya dilakukan proses pengecilan ukuran dari bonggol jagung agar diperoleh luas kontak yang lebih besar sehingga daya serap juga lebih tinggi.

Selanjutnya di tahap karbonisasi, sekam padi dan bonggol jagung dimasukkan kedalam wadah dan dimasukkan dalam furnace untuk dikarbonisasi. Proses karbonisasi ini berlangsung pada suhu $300^{\circ} \mathrm{C}$ selama \pm 40 menit. Setelah itu dinginkan dalam suhu ruang. Selanjutnya digerus dan disieving pada 60 mesh.

Pada proses aktifasi, arang sekam padi dan arang bonggol jagung di aktivasi menggunakan $\mathrm{H}_{3} \mathrm{PO}_{4} 5 \%, 10 \%, 15 \%, 20 \%$ dan $25 \%$ kemudian diaduk selama 10 menit dan didiamkan selama 24 jam kemudian campuran tersebut disaring dan cakenya dicuci dengan aquadest. Cake tersebut dicuci sampai mendapatkan pH yang mendekati netral kemudian dikeringkan dalam oven pada suhu sekitar $110^{\circ} \mathrm{C}$ dan didinginkan dalam desikator.

Setelah proses persiapan karbon aktif, selanjutnya tahapan adsorbansi dengan air sungai sekanak yang digunakan sebagai sampel dan karbon aktif sebagai adsorber. Tahapan perendaman selama 24 jam, setelah itu baru di cek kadar COD, BOD, TDS, pH, dan Fe (Fe ${ }^{2+}$, $\mathrm{Fe}^{3+}$ terlarut, dan $\mathrm{Fe}^{3+}$ ) dengan menggunakan instrument spektrofotomer.

\section{HASIL DAN PEMBAHASAN}

Penentuan Kadar Air Karbon Aktif (ASTM of standar D 3173 - 2003) 
Penentuan kadar air pada karbon aktif digunakan untuk mengetahui sifat higroskopis. Dengan bertambahnya luas permukaan karbon aktif tersebut akan meningkatkan sifat higroskopis. Karbon aktif yang memiliki kelembaban lebih rendah dari kelembaban udara, akan membuat karbon aktif mengadsorbsi udara di sekitar sehingga membuat kadar air di dalam karbon aktif menjadi meningkat.

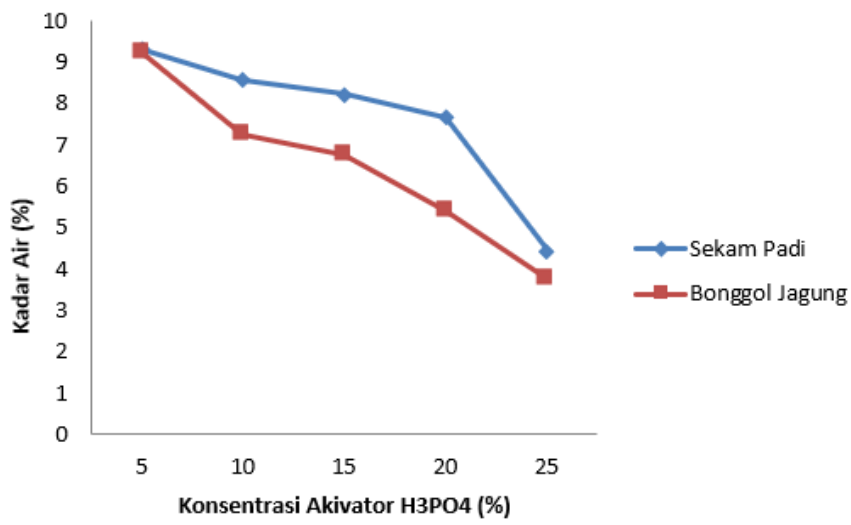

Gambar 1. Grafik hubungan antara konsentrasi aktivator $\mathrm{H}_{3} \mathrm{PO}_{4}$ terhadap kadar air karbon aktif

Berdasarkan gambar 1, dapat dilihat bahwa semakin tinggi konsentrasi aktivator maka kadar air dari karbon aktif cenderung semakin kecil. Untuk sekam padi memiliki kadar air lebih tinggi, yaitu sebesar $9,3 \%$ hingga $4,45 \%$, sedangkan karbon aktif dari bonggol jagung memiliki kadar air sebesar $9,22 \%$ hingga 3,76\%. Kecendrungan perbedaan jenis karbonisasi dan variasi konsentrasi aktivator $\mathrm{H}_{3} \mathrm{PO}_{4}$ mengakibatkan perbedaan antara karakteristik karbon aktif seperti kadar air. Sedangkan, kadar air akan mengalami penurunan seiring dengan bertambahnya konsentrasi aktivator. Dari perbedaan karbonisasi, kadar air sekam padi lebih besar dari kadar air pada bonggol jagung. Berdasarkan sampel yang telah diujikan, diketahui bahwa kadar air karbon aktif telah memenuhi standar mutu karbon aktif berdasarkan SNI 06 - 3730 - 1995 yaitu dengan kadar air maksimal 15\%. Rendahnya kadar air ini menunjukkan bahwa kandungan air bebas dan air terikat yang terdapat dalam bahan telah menguap selama proses karbonisasi.

\section{Penentuan Kadar Abu Karbon Aktif (ASTM standard D 3174 - 2004)}

Selain kadar air, dilakukan juga uji kualitas karbon aktif dengan menganalisa kadar abu. Kadar abu akan mempengaruhi kualitas karbon aktif sebagai absorber. Abu yang dihasilkan berupa oksida - oksida logam yang terdiri dari mineral yang tidak dapat menguap pada pengabuan.

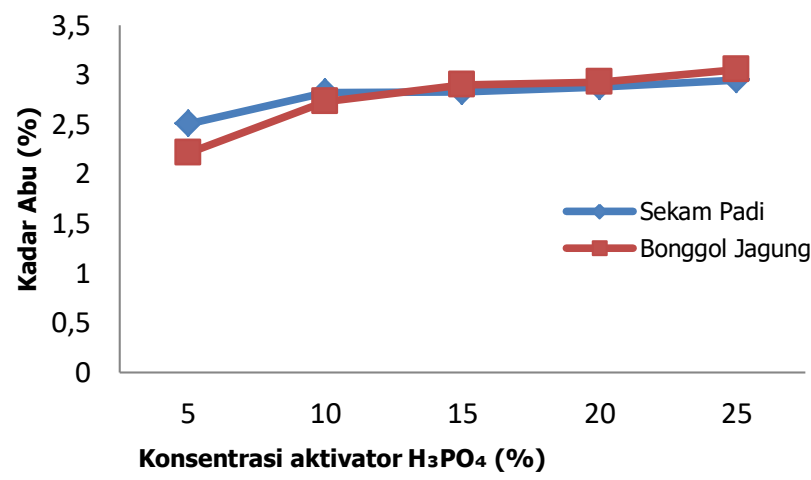

Gambar 2. Grafik hubungan antara konsentrasi aktivator $\mathrm{H}_{3} \mathrm{PO}_{4}$ terhadap kadar abu karbon aktif 
Dari Gambar 2 dapat dilihat semakin bertambahnya konsentrasi aktivator maka abu yang didapatkan semakin besar. Kadar abu pada sekam padi dengan konsentrasi aktivator 5 - 25\% mencapai 2,21 - 3,05\%, sedangkan kadar abu pada bonggol jagung dengan konsentrasi aktivator 5 - 25\% mencapai 2,51 -2,95\%. Berdasarkan hasil analisa yang diperoleh, diketahui bahwa mutu dari karbon aktif sudah memenuhi standar berdasarkan SNI 06 - 3730 - 1995 syarat standar mutu karbon aktif maksimal $10 \%$. Kadar abu yang diinginkan adalah serendah mungkin sehingga adsorpsi cairan dapat berlangsung lebih baik. Hal ini disebabkan karena kandungan mineral dalam abu seperti kalsium, kalium, magnesium dan natrium dapat menyebar dalam kisi-kisi arang aktif dan menutupi pusat aktif serta dapat mengurangi kemampuan karbon aktif untuk menyerap gas atau larutan.

\section{Penentuan Daya Serap Iod}

Penentuan daya serap terhadap iod bertujuan untuk memperkirakan porositas bahan aktif dan untuk memberikan indikasi terhadap besarnya pori yang dimasuki oleh molekul - molekul berdiameter kecil.

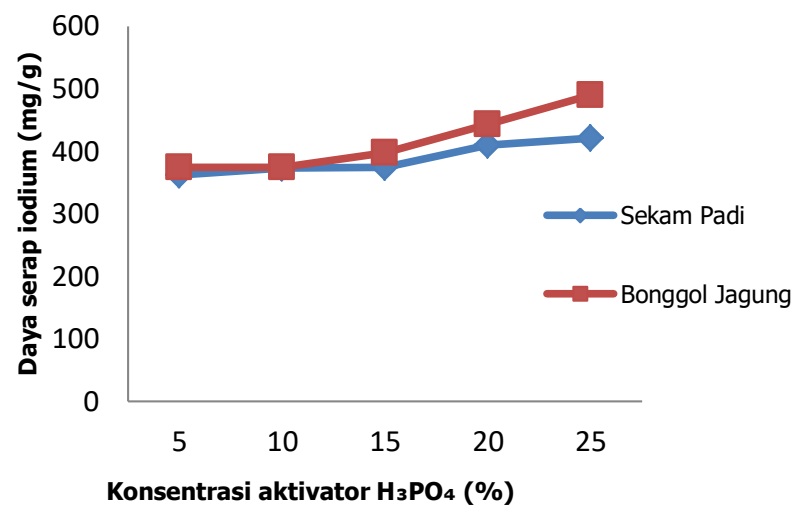

Gambar 3. Grafik hubungan antara konsentrasi aktivator $\mathrm{H}_{3} \mathrm{PO}_{4}$ dengan daya serap iodium dari karbon aktif

Berdasarkan Gambar 3 diketahui daya serap iod dari karbon aktif berkisar antara 300 - 500 $\mathrm{mg} / \mathrm{g}$. Daya serap iod tertinggi karbon aktif dari bonggol jagung pada konsentrasi aktivator 25 $\%$ yaitu $421,26 \mathrm{mg} / \mathrm{g}$ sedangkan pada bonggol jagung yang tertinggi pada konsentrasi aktivator $25 \%$ yaitu $489,91 \mathrm{mg} / \mathrm{g}$.

Menurut SNI 06 - 3730 - 1995, syarat mutu karbon aktif yang harus memenuhi standar terhadap daya serap iod mencapai minimal $20 \%(200 \mathrm{mg} / \mathrm{g})$. Daya serap iod ini menentukan karbon aktif yang paling baik untuk mengolah limbah cair maupun gas.

Jenis dari karbon dan konsentrasi yang digunakan untuk aktivasi karbon mempengaruhi kualitas dari karbon aktif yang dihasilkan, semakin tinggi konsentrasi aktivator maka semakin banyak daya serap iod karena pori - pori dari karbon aktif menjadi lebih besar serta kualitas dari kadar air terikat, kadar abu, dan luas permukaan akan memperngaruhi daya absorpsi dari karbon aktif itu sendiri. Kondisi optimum didapat pada perendaman selama 24 jam, semakin lama perendaman daya serapnya semakin besar hingga pada waktu 24 jam, daya serap terhadap larutan iodium semakin tinggi (Sani, 2011).

\section{Analisis pH pada Air Sungai Sekanak setelah Perlakuan Menggunakan Karbon Aktif}

Analisis $\mathrm{pH}$ bertujuan untuk mengetahui $\mathrm{pH}$ yang dihasilkan setelah kontak dengan karbon aktif. Hasil analisis pH dalam air Sungai pada penelitian ini dapat dilihat pada Gambar 4. 


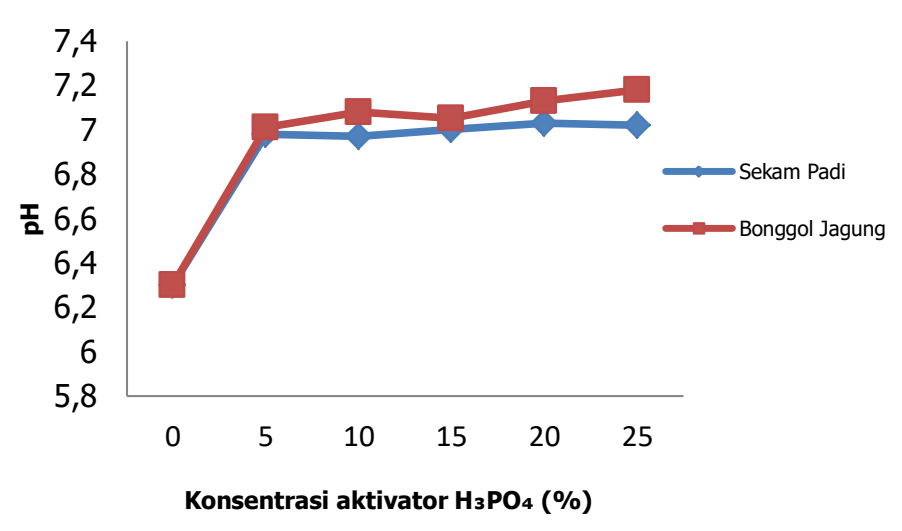

Gambar 4. Grafik pH Sungai Sekanak

Berdasarkan dari Gambar 4 menunjukkan bahwa air Sungai Sekanak setelah perlakuan menggunakan karbon aktif sekam padi maupun bonggol jagung mengalami kenaikan $\mathrm{pH}$ yang memenuhi range standar baku mutu $6-9$, sehingga dapat dilihat bahwa keefektifitasan karbon aktif sekam padi dan bonggol jagung baik dalam meningkatkan nilai pH. Kualitas air dipengaruhi oleh $\mathrm{pH}$ yang terkandung dalam air tersebut. Air yang berkualitas yaitu apabila air itu memiliki pH sekitar 7. Sehingga apabila air memiliki pH kurang dari 7 maka air akan bersifat asam, namun bila air lebih dari 7 maka air akan bersifat basa. (Azwir, 2006)

\section{Analisis BOD}

Kandungan BOD merupakan indikasi dari pengukuran jumlah oksigen yang dibutuhkan oleh bakteri untuk mengurai hampir semua zat organik yang terlarut pada air Sungai Sekanak.

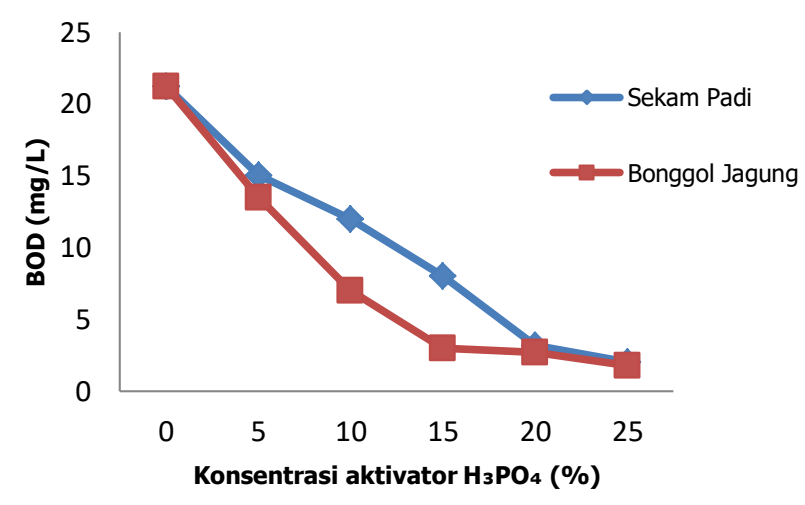

Gambar 5. Grafik Kandungan BOD Sungai Sekanak

Berdasarkan dari Gambar 5 menunjukkan bahwa kandungan BOD di dalam air Sungai Sekanak melebihi baku mutu yang telah ditetapkan yaitu $21,2 \mathrm{mg} / \mathrm{L}$ sedangkan baku mutu yang ditetapkan pada peraturan gubernur Sumsel nomor 16 tahun 2005 sebesar 3 mg/L.

Sampel air sungai yang dikontakkan terhadap karbon aktif memiliki nilai BOD yang cenderung menurun, jika di tinjau dari semakin besarnya konsentrasi activator yang digunakan. Pada konsentrasi activator $25 \%$, nilai BOD dari sampel air sungai yang di kontakkan dengan karbon aktif dari bonggol jagung sebesar $1,8 \mathrm{mg} / \mathrm{L}$ dan $2 \mathrm{mg} / \mathrm{L}$ nilai BOD dari sampel air sungai yang di kontakkan dengan karbon aktif dari sekam padi. 


\section{Analisis COD}

Analisis COD pada air Sungai dilakukan untuk mengetahui jumlah kandungan oksigen yang dibutuhkan untuk menguraikan bahan tak larut. Analisis COD ini merupakan indikasi ukuran bagi pencemaran air oleh zat organik yang secara alamiah dapat dioksidasi melalui proses biologis dan dapat menyebabkan berkurangnya oksigen terlarut dalam air dan hasil analisis COD dalam air Sungai Sekanak

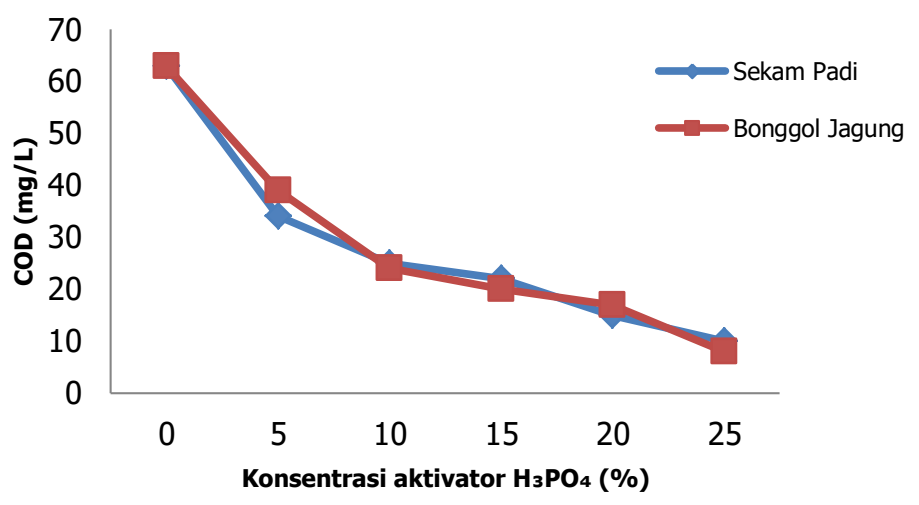

Gambar 6. Grafik Kandungan COD Sungai Sekanak

Berdasarkan dari Gambar 6 menunjukkan bahwa kandungan COD di dalam air Sungai Sekanak melebihi baku mutu yang telah ditetapkan yaitu $63 \mathrm{mg} / \mathrm{L}$ sedangkan baku mutu yang ditetapkan pada peraturan gubernur Sumsel nomor 16 tahun 2005 sebesar 25 mg/L. Sampel air sungai yang dikontakkan terhadap karbon aktif memiliki nilai COD yang cenderung menurun, jika di tinjau dari semakin besarnya konsentrasi activator yang digunakan. Pada konsentrasi activator $25 \%$, nilai COD dari sampel air sungai yang di kontakkan dengan karbon aktif dari bonggol jagung sebesar $8 \mathrm{mg} / \mathrm{L}$ dan $10 \mathrm{mg} / \mathrm{L}$ nilai COD dari sampel air sungai yang di kontakkan dengan karbon aktif dari sekam padi.

\section{Analisis TDS}

TDS (Total Dissolve Solid) yaitu ukuran zat terlarut yang terdapat pada sebuah larutan. TDS meter merupakan alat uji yang dapat menggambarkan jumlah zat terlarut dalam Part Per Million (PPM) atau sama dengan milligram per Liter (mg/L). Pada air Sungai Sekanak memiliki kandungan TDS yaitu $161 \mathrm{mg} / \mathrm{L}$. Kandungan pada air Sungai Sekanak ini melebihi baku mutu yang ditetapkan pada peraturan gubernur Sumsel nomor 16 tahun 2005 sebesar 50 mg/L. Hasil analisis TDS dalam air Sungai pada penelitian ini dapat dilihat pada Gambar 7.

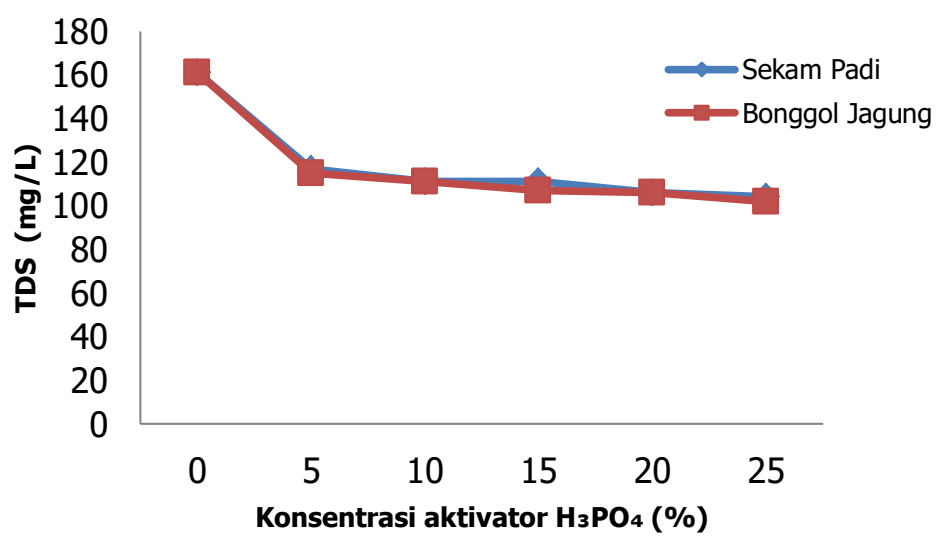

Gambar 7. Grafik Kandungan TDS Sungai Sekanak 
Berdasarkan dari Gambar 7 menunjukkan kandungan TDS di dalam air Sungai Sekanak melebihi baku mutu yang telah ditetapkan yaitu $161 \mathrm{mg} / \mathrm{L}$ sedangkan baku mutu yang ditetapkan pada peraturan gubernur Sumsel nomor 16 tahun 2005 sebesar 50 mg/L. Untuk TDS, jika ditinjau dari setelah adanya kontak antara sampel air sungai sekanak terhadap karbon aktif. Nilai TDS cenderung menurun seiringnya semakin besarnya konsentrasi dari aktivator yang digunakan. Pada konsentrasi aktivator 25\%, kandungan TDS dari sampel yang dikontakkan dengan bonggol jagung sebesar $102 \mathrm{mg} / \mathrm{L}$ dan $104 \mathrm{mg} / \mathrm{L}$ untuk sampel yang dikontakkan dengan karbon aktif dari sekam padi. Berdasarkan data dari hasil analisa ini diketahui bahwa nilai TDS dari sampel air sungai yang dikontakkan masih di atas dari baku mutu, tapi sudah menurun ari nilai TDS awal dari sampel air sungai yang belum dikontakkan dengan karbon aktif.

\section{Analisis Besi}

Pada air Sungai Sekanak memiliki kandungan besi yaitu $0,09 \mathrm{mg} / \mathrm{L}$ sedangkan baku mutu yang ditetapkan pada peraturan gubernur Sumsel nomor 16 tahun 2005 sebesar 0,3 mg/L. Hasil kandungan besi pada air Sungai Sekanak setelah perlakuan karbon aktif dari sekam padi dan bonggol jagung dapat dilihat pada Gambar 8.

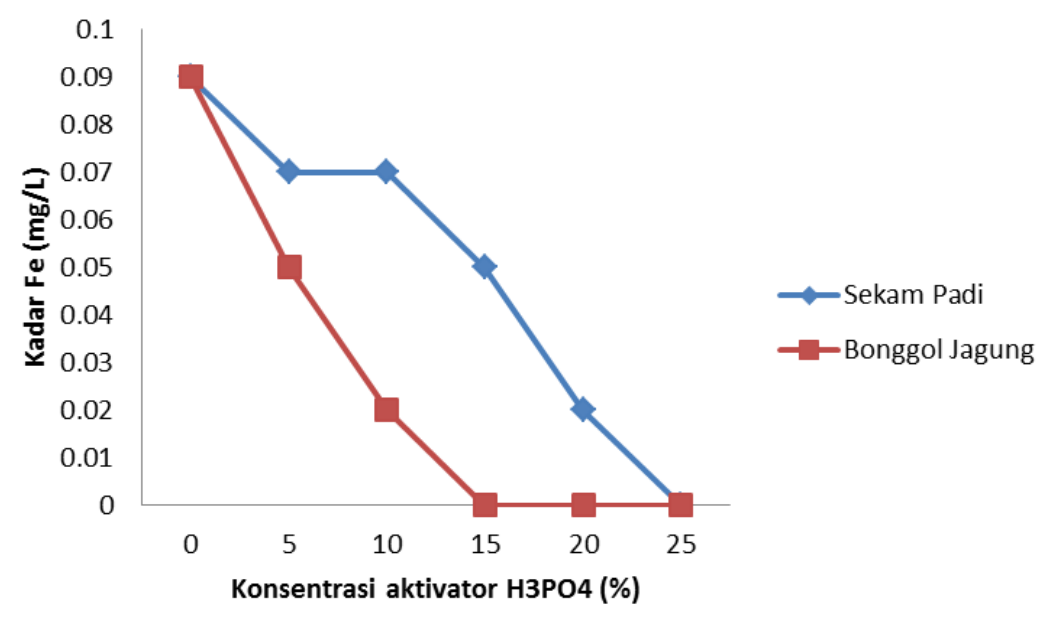

Gambar 8. Grafik hubungan Kandungan besi dengan konsentrasi aktivator

Berdasarkan Gambar 8, diketahui bahwa kadar Fe cenderung menurun dan masuk kedalam baku mutu air. Berdasarkan peraturan Gubernur Sumsel Nomor 16 Tahun 2005 batas maksimal kandungan $\mathrm{Fe}$ di dalam air sebesar 0,3mg/L. Karbon aktif dari sekam padi cenderung lebih rendah penurunannya di bandingkan dengan karbon aktif dari bonggol jagung, walupun besar konsentrasi aktivator yang digunakan sama. Terdapat rasio yang cukup besar antara kadar fe yang tersisa di air sungai, yaitu pada konsentrasi $5 \%$ hingga $20 \%$. Walaupun pada konsentrasi $25 \%$, kadar Fe yang terdapat dalam air sungai baik yang di kontakkan dengan karbon aktif dari bonggol jagung dan juga sekam padi berada di titik yang sama, yaitu sebesar Omg/L kandungan Fe yang terdapat di dalam air sungai yang di uji sebagai sampel.

\section{KESIMPULAN}

Kualitas karbon aktif dipengaruhi oleh bahan baku, kondisi operasi pada tahap karbonisasi, serta konsentrasi aktivator yang digunakan. Berdasarkan penelitian yang telah dilakukan diperoleh bahwa karbon aktif terbaik berasal dari bonggol jagung, yang diaktivasi dengan $\mathrm{H}_{3} \mathrm{PO}_{4}$ $25 \%$ dan di karbonisasi pada suhu $300^{\circ} \mathrm{C}$. Penggunaan arang aktif bonggol jagung dengan konsentrasi $\mathrm{H}_{3} \mathrm{PO}_{4} 25 \%$ sebagai adsorben pada pengolahan air sungai sekanak dapat 
menurunkan nilai COD dari $63 \mathrm{mg} / \mathrm{L}$ menjadi $8 \mathrm{mg} / \mathrm{L}$, BOD dari 21,2 mg/L menjadi 1,5 mg/L, TDS dari $161 \mathrm{mg} / \mathrm{L}$ menjadi $102 \mathrm{mg} / \mathrm{L}$, Fe dari $0,09 \mathrm{mg} / \mathrm{l}$ menjadi $0 \mathrm{mg} / \mathrm{l}$ sedangkan nilai $\mathrm{pH}$ meningkat dari 6,3 menjadi 7,18. Arang aktif dari bonggol jagung memiliki spesifikasi antara lain, kadar air sebesar 3,76\%, kadar abu sebesar 3,05\% dan untuk daya serap terhadap iodium karbon aktif dari bonggol jagung sebesar $489,91 \mathrm{mg} / \mathrm{g}$.

\section{DAFTAR PUSTAKA}

Akhmad B, dkk. 2012. Pengaruh Temperatur Karbonisasi dan Konsentrasi Zink Klorida Terhadap Luas Permukaan Karbon Aktif Enceng Gondok. Teknik Material dan Metalurgi. ITS.

Azwir. 2006. Analisa Pencemaran Air Sungai Tapung Kiri Oleh Limbah Industri Kelapa Sawit PT. Peputra Masterindo di Kabupaten Kampar. S2, Universitas Diponegoro.

Budiono A, Suhartana, Gunawan. 2009. Pengaruh Aktivasi Arang Tempurung Kelapa Dengan Asam Sulfat Dan Asam Fosfat Untuk Adsorpsi Fenol. Semarang (ID) : Universitas Diponegoro.

Effendi. 2003. TelaahKualitas Air Bagi Pengelolaan Sumber Daya dan Lingkungan Perairan. Penerbit Kanisisus, Yogyakarta.

Faujiah F. 2012. Pemanfaatan Karbon Aktif Dari Limbah Padat Industri Agar - Agar Sebagai Adsorben Logam Berat Dan Bahan Organik Dari Limbah Industri Tekstil [Skripsi].Bogor (ID) : Institut Pertanian Bogor.

Haryadi. 2006. Teknologi Pengolahan Beras. Jakarta Gajah Mada Universitas Press, (UI Press)

Hendra. 2008. Jurnal Pembuatan Arang Aktif Dari Tempurung Kelapa Sawit dan Serbuk Gergaji Campuran.Jakarta.

Keputusan Peraturan Gubernur Sumatera Selatan Nomor 16, 2005. Tentang Baku Mutu Air Sungai, Palembang

Kurniati. 2008. Jurnal Pemanfaatan Cangkang Sawit Sebagai Arang Aktif. Jawa Timur : Teknik Kimia FTI - UPN "Veteran".

Rahmawati. 2012. Studi Adsorpsi Logam Pb (II) dan Cd (II) Pada Asam Humat Dalam Medium Air. Alchemy.2(1) : 46-57

Sani. 2011. Pembuatan Karbon Aktif Dari Tanah Gambut. Jawa Timur : Teknik Kimia Fakultas Teknologi Industri " Veteran".

Soemarwoto. 2003. Atur Diri Sendiri Paradigma Baru Pengelolaan Lingkungan Hidup. Yogyakarta : Gadjah Mada University Press.

Sembiring, M.T, dkk. 2003. Arang Aktif Pengenalan dan Proses Pembuatannya. Sumatera: Universitas Sumatera Utara.

Septiningrum. 2011. "Produksi Xilanase dari Tongkol Jagung Dengan Sistem Bioproses menggunakan Bacillus Circulans untuk Pra-Pemutihan Pulp Production Of Xynase From Corncob by Bioprocess System Using Bacillus Circulans For Pre Bleaching Pulp". Bandung : Balai Besar Pulp dan Kertas, Kementerian Perindustrian Indonesia. Vol V, No. 1 Hal. 8797.

Sitanggang, Crismasly., 2015. Pemanfaatan Arang Sekam Padi Sebagai Adsorben Untuk Menurunkan Kadar Besi Dalam Air Sumur. Sumatera: Universitas Sumatera Utara.

Suryani. 2009. Pemanfaatan Bonggol Jagung Untuk Pembuatan Arang Aktif Sebagai Adsorben Pemurnian Minyak Goreng Bekas. Skripsi Departemen Kimia Fakultas MIPA IPB Bogor.

Yustinah. 2011. Adsorpsi Minyak Goreng Bekas Menggunakan Arang Aktif dari Sabut Kelapa. Prosiding Seminar Nasional Teknik Kimia. ISSN 1693 - 4393. Yogyakarta. 